\title{
Physician Prescribing Patterns of Oral Corticosteroids for Musculoskeletal Injuries
}

\author{
Kimberly G. Harmon, MD, and Chris Hawley, MD
}

Background: There is considerable controversy as to when and if oral corticosteroids are indicated for musculoskeletal injury. Although the perception is that sports medicine physicians prescribe oral corticosteroids frequently, there is no documentation of this behavior in the literature. The purpose of this study was to obtain a description of the corticosteroid-prescribing patterns of primary care sports medicine physicians and look for common indications.

Methods: A two-page questionnaire was included in the registration packets of 195 physicians at a national sports medicine conference.

Results: Ninety-nine questionnaires were returned. Fifty-eight $(58.6 \%)$ of the physicians reported prescribing oral corticosteroids for musculoskeletal injuries. Physicians who prescribed corticosteroids for injuries averaged 6.6 prescriptions per month. Prednisone was the corticosteroid prescribed by $82 \%$ of physicians. The average prescription length was 7 days. One half of the physicians $(51.7 \%)$ tapered the dose. The most common starting dose (mode) was $60 \mathrm{mg}$.

Conclusions: Despite little evidence to support their use, primary care sports medicine physicians commonly prescribe corticosteroids. (J Am Board Fam Pract 2003;16:209-12.)

Corticosteroids are the most potent anti-inflammatory medications available to the physician. The treatment of many sports injuries includes attempts to reduce inflammation through the use of such modalities as ice, nonsteroidal anti-inflammatories (NSAIDs), and, sometimes corticosteroid medicatons. To date, there is no documentation regarding physician prescribing patterns of oral corticosteroids. Many authors believe there is no role for the use of oral corticosteroids in sports injuries. ${ }^{1-5}$ In practice, although, it seems they are used frequently.

The rationale for use of anti-inflammatory therapy is that by controlling inflammation, the amount of damage to the injured tissue will be limited, rehabilitation will be enhanced, and return to play will be expedited. Although corticosteroids are potent inhibitors of inflammation, they are also catabolic and can impair wound healing. ${ }^{6-8}$ Inflammation is the precursor to repair. Without some initial inflammation, healing cannot progress to further

Submitted, revised, 18 March 2002.

From the Department of Family Medicine (KGH), and the Department of Orthopaedics and Sports Medicine (KGH), Hall Health Sports Medicine Clinic, University of Washington, Seattle; and the Sports Medicine Clinic $(\mathrm{CH})$ University of Texas at Austin. Address reprint requests to Kimberly G. Harmon, MD, 4110 NE 142nd St, Seattle, WA 98125 . stages. ${ }^{7}$ There are few trials assessing the efficacy or safety of oral corticosteroids in nondiscogenic musculoskeletal conditions. Their use for musculoskeletal injuries appears to receive some anecdotal support. ${ }^{9}$ How widespread the use of oral corticosteroids and the prescribing patterns of physicians is unknown, however.

\section{Methods}

To obtain a description of the corticosteroid-prescribing patterns of sports medicine physicians, a two-page questionnaire was included in the registration packets of a national sports medicine meeting. Permission for distribution of the questionnaire was obtained from the sponsoring organization. This conference was attended by family physicians, internists, pediatricians, emergency medicine physicians, and physiatrists with interest and expertise in the practice of sports medicine. None of the attendants was an orthopedic surgeon. Personal identity of the surveyed physicians was not solicited. Limited demographic data were collected to assess prescription patterns of physicians in different regions, specialties, and experience levels. No data were collected from nonresponders. Completion of the survey was entirely voluntary.

Physician oral corticosteroid prescribing frequency for musculoskeletal injuries was collected using open-ended questions based on average pre- 
Table 1. Specialty and Corticosteroid-Prescribing Patterns for Survey Participants.

\begin{tabular}{lcc}
\hline & $\begin{array}{c}\text { Percent Who Prescribe } \\
\text { Corticosteroids for } \\
\text { Musculoskeletal } \\
\text { Specialty }\end{array}$ & $\begin{array}{c}\text { Number } \\
\text { Family practice }\end{array}$ \\
\hline Internal medicine & 74 & 56.8 \\
Pediatrics & 13 & 69.2 \\
Physical medicine and & 2 & 50.0 \\
rehabilitation & 1 & 100.0 \\
Sports medicine & 1 & 0.0 \\
Emergency medicine & 1 & 0.0 \\
Total & 99 & 58.6 \\
\hline
\end{tabular}

scriptions written per month. Survey participants were also asked to examine a list of both acute and chronic sports medicine injuries and indicate whether they would consider prescribing oral corticosteroids for these injuries. An open-ended response was also included for other injuries that might not have been included on the questionnaire. Physicians who prescribe oral corticosteroids were asked to indicate on a 6-point Likert scale the relative importance of various factors in their decision of whether to use oral corticosteroids. A 0 score was assigned to an unimportant factor and a 5 was assigned to a very important factor. Physicians who did not prescribe oral corticosteroids were asked to rate the relative importance of a variety of factors that they used to make their decision against corticosteroids on a similar Likert scale. The mean scores for each factor were calculated and ranked to determine their relative importance in the physicians' decision-making process. A descriptive analysis was undertaken of the results.

\section{Results}

One hundred ninety-five questionnaires were included in registration packets given at the start of the conference. Ninety-nine were completed for a $51 \%$ return rate. Fifty-eight $(58.6 \%)$ of the physi-
Table 2. Injury Indications for Corticosteroids by Surveyed Physicians.

\begin{tabular}{ll}
\hline Injury Indication & $\%($ No.) \\
\hline Acute conditions only & $32.7(19)$ \\
Chronic conditions only & $31.0(18)$ \\
Acute and chronic conditions & $36.2(21)$ \\
\hline
\end{tabular}

cians reported ever prescribing oral corticosteroids for musculoskeletal injuries (Table 1). Physicians who prescribed corticosteroids for injuries averaged 6.6 prescriptions per month. Prednisone was the corticosteroid used by $82 \%$ of physicians. The average prescription length was 7 days. One half $(51.7 \%)$ of the physicians tapered the dose. The most common starting dose (mode) was $60 \mathrm{mg}$.

There was no consensus among corticosteroidprescribing physicians on indications for use. Approximately one third of physicians reported prescribing corticosteroids for acute conditions, one third for chronic conditions, and one third for both acute and chronic conditions (Table 2).

Those who received additional fellowship training in sports medicine or those holding a certificate of added qualifications in sports medicine appeared to be more likely to prescribe corticosteroids for nondiscogenic musculoskeletal conditions than did those who did not have additional training. There was a trend toward increased oral corticosteroid use with more practice experience (Table 3).

Among physicians who used corticosteroids to treat musculoskeletal injury, severity of injury was the primary factor in decision to prescribe. Among physicians who do not use oral corticosteroids, lack of medical literature supporting efficacy was the primary reason given for not prescribing (Table 4).

\section{Discussion}

There is limited research into the use of oral corticosteroids for nondiscogenic back pain. In three randomized, double-blind, placebo controlled

Table 3. Training and Experience Characteristics of Surveyed Physicians.

\begin{tabular}{lccccc}
\hline & & \multicolumn{3}{c}{ Years in Practice } \\
\cline { 5 - 6 } $\begin{array}{l}\text { Prescribe } \\
\text { Corticosteroids }\end{array}$ & $\begin{array}{c}\text { Fellowship } \\
\text { Trained } \\
\%\end{array}$ & $\begin{array}{c}\text { Added } \\
\text { Qualifications } \\
\%\end{array}$ & $\begin{array}{c}0 \text { to } 10 \\
\%(\text { No.) }\end{array}$ & $\begin{array}{c}11 \text { to } 20 \\
\%(\text { No.) }\end{array}$ & $\%$ (No.) \\
\hline Yes & 56.9 & 61.8 & $55.2(37)$ & $58.8(10)$ & $61.5(8)$ \\
No & 43.1 & 38.2 & $44.8(30)$ & $41.2(7)$ & $38.5(5)$ \\
\hline
\end{tabular}


Table 4. Relative Importance of Factors for Physicians Who Prescribe and Do Not Prescribe Corticosteroids for Musculoskeletal Injuries.

\begin{tabular}{lc}
\hline Physician Factor & $\begin{array}{c}\text { Mean Likert } \\
\text { Score* }\end{array}$ \\
\hline $\begin{array}{l}\text { Prescribe corticosteroids } \\
\quad \text { Severity of injury }\end{array}$ & 3.82 \\
$\quad$ Failure of modalities (ice, electric & 3.30 \\
$\quad$ stimulation, etc) & 3.24 \\
$\quad$ Failure of nonsteroidal anti-inflammatory & \\
$\quad$ medication & 3.09 \\
$\quad$ Urgency of return to play for athlete & 3.09 \\
$\quad$ Failure of rehabilitative exercises & 2.96 \\
$\quad$ Failure of relative rest & 2.86 \\
$\quad$ Level of play of athlete & \\
$\quad \begin{array}{l}\text { Do not prescribe corticosteroids } \\
\text { Lack of medical literature regarding }\end{array}$ & 4.27 \\
$\quad$ Lackicacy & 4.13 \\
$\quad$ Fear of side effects & 3.81 \\
\hline
\end{tabular}

*In which $0=$ unimportant factor and $5=$ very important factor.

studies, patients with carpal tunnel syndrome showed temporary benefit from oral corticosteroids. ${ }^{10-12}$

There are no human studies evaluating the use of oral corticosteroids in acute injuries, such as contusion, strains, or sprains. Some animal studies, however, have evaluated systemic steroids (intramuscular injection) for contusions. ${ }^{13,14}$ The steroids were given in dosages higher than those typically given to humans and were continued for longer durations. Histologic studies of injured tissue showed a decrease in initial inflammation but eventual decreased tensile strength of the affected tissue with the use of corticosteroids compared with controls. Direct injection of corticosteroids into a muscle defect after a strain is sometimes used in elite athletes and has been retrospectively reviewed. ${ }^{15}$ Results appeared promising; however, there was no control group and outcome measures were subjective.

Some authors advocate use of oral corticosteroids for adhesive capsulitis, but this recommendation is not based on any studies. ${ }^{16,17}$ The use of corticosteroids for chronic tendonitis is suspect, because this condition is degenerative rather than inflammatory. ${ }^{2,18}$

Corticosteroids have been prescribed extensively for a multitude of conditions, and their side effects are well documented. Serious side effects are most likely with prolonged or high-dose use. There is little documentation of incidence of side effects or risk with short-term (less than 1 week) and medium-dose (about $1 \mathrm{mg} / \mathrm{kg}$ ) use of corticosteroids. The most common side effects with shortterm, medium-dose steroids are changes in appetite and sleep pattern. ${ }^{19}$

Physicians that did not prescribe oral corticosteroids for musculoskeletal conditions might have been more likely not to complete and return the survey. Even so, it is important to note that many sports medicine physicians are prescribing oral corticosteroids, and there is no consensus on indications for their use. The demographic profile of the physicians surveyed was fairly narrow. Meeting attendees were primary care physicians with expertise in sports medicine. Prescribing patterns of orthopedic surgeons or physicians who do not practice much sports medicine might vary.

\section{Conclusion}

The use of oral corticosteroids as treatment of sports injuries is common. There is scant literature to support steroid use for most sports injuries. Animal studies that have examined the effect of corticosteroids on healing are not strictly applicable to human injury models. Injuries, dosages, length of treatment, and routes of administration might not be typical of the human sports injury. Because of the widespread use of oral corticosteroids and the anecdotal support they receive from clinicians, more research should be conducted on the efficacy of corticosteroids in different types of injuries. Serious side effects are possible but unlikely given typical dosing patterns.

\section{References}

1. Almekinders LC. Anti-inflammatory treatment of muscular injuries in sport. An update of recent studies. Sports Med 1999;28:383-8.

2. Almekinders LC, Deol G. The effects of aging, antiinflammatory drugs, and ultrasound on the in vitro response of tendon tissue. Am J Sports Med 1999; 27:417-21.

3. Behrens TW, Goodwin JS. Oral corticosteroids. In: Leadbetter WB, Buckwalter JA, Gordon SL, editors. Sports-induced inflammation. Rosemont, Ill: American Academy of Orthopaedic Surgeons, 1990:40520.

4. Cox JS. Current concepts in the role of steroids in 
the treatment of sprains and strains. Med Sci Sport Exerc 1984;16:216-8.

5. Leadbetter WB. Anti-inflammatory therapy in sports injury. The role of nonsteroidal drugs and corticosteroid injection. Clin Sports Med 1995;14: 353-410.

6. Almekinder LC. Anti-inflammatory treatment of muscular injuries in sports. Sports Med 1993;15: $139-45$.

7. Fantone JC. Basic concepts in inflammation. In: Leadbetter WB, Buckwalter JA, Gordon SL, editors. Sports-induced inflammation. Rosemont, Ill: American Academy of Orthopaedic Surgeons, 1990:2554.

8. Hickson RC, Czerwinski SM, Falduto MT, Young AP. Glucocorticoid antagonism by exercise and androgenic-anabolic steroids. Med Sci Sports Exerc 1990;22:331-40.

9. Beiner JM, Jokl P. Muscle contusion injuries: current treatment options. J Am Acad Orthop Surg 2001;9: 227-37.

10. Chang MH, Chiang HT, Lee SS, Ger LP, Lo YK. Oral drug of choice in carpal tunnel syndrome. Neurology 1998;51:390-3.

11. Herskovitz S, Berger AR, Lipton RB. Low-dose, short-term oral prednisone in the treatment of carpal tunnel syndrome. Neurology 1995;45:1923-5.

12. Wong SM, Hui AC, Tang A, et al. Local vs systemic corticosteroids in the treatment of carpal tunnel syndrome. Neurology 2001;56:1565-7.

13. Beiner JM, Jokl P, Cholewicki J, Panjabi MM. The effect of anabolic steroids and corticosteroids on healing of muscle contusion injury. Am J Sports Med 1999;27:2-9.

14. Jarvinen M, Lehto M, Sorvari T, et al. Effect of some anti-inflammatory agents on the healing of ruptured muscle. An experimental study in rats. J Sports Trumatol Rel Res 1992;14:19-28.

15. Levine WN, Bergfeld JA, Tessendorf W, Moorman CT 3rd. Intramuscular corticosteroid injection for hamstring injuries. A 13 -year experience in the $\mathrm{Na}$ tional Football League. Am J Sports Med 2000;28: 297-300.

16. Pearsall AW, Speer KP. Frozen shoulder syndrome: diagnostic and treatment strategies in the primary care setting. Med Sci Sport Exerc 1998;30(4 Suppl): S33-9.

17. Noel E, Thomas T, Schaeverbeke T, Thomas P, Bonjean M, Revel M. Frozen shoulder. Joint Bone Spine 2000;67:393-400.

18. Martens M, Wouters P, Burssens A, Mulier JC. Patellar tendinitis: pathology and results of treatment. Acta Orthop Scand 1982;53:445-50.

19. Goroll AH, May LA, Mulley AG Jr, editors. Primary care medicine, office evaluation and management of the adult patient office evaluation and management of the adult patient, ed 3. Philadelphia: LippincottRaven, 1995:578-82. 